\title{
CHARACTERIZATION AND MODELING OF ADVANCED OPEN-POROUS COPPER HEAT EXCHANGER MATERIALS
}

\author{
JAKUB SKIBINSKI \\ Faculty of Materials Science and Engineering, Warsaw University of Technology, Poland
}

\begin{abstract}
Open-porous copper foams applied as heat exchanger materials are addressed within the study. Commercially available materials are characterized with the use of microcomputed tomography. The results of materials characterization act as assumptions for the development of a numerical design procedure, with the ability to control the selection of porous structure parameters, including constrictivity and pore size distribution. An adaptation of Laguerre-Voronoi tessellations is performed allowing for exact representation of complex porous structures. The design algorithm has been developed in such a way as to enable determination of the influence of pore size distribution on utility properties such as temperature transfer efficiency.
\end{abstract}

Keywords: copper foams, open-porous materials, Laguerre-Voronoi tessellations.

\section{INTRODUCTION}

Open-porous copper foams are high performance materials with high thermal conductivity and high specific strength. These features make such materials attractive for application in cross-flow heat exchangers, catalytic converters, electrodes of high-temperature fuel cells or solar collectors [1], [2], where high performance materials with thermal conductivity being an essential factor are required.

Structural parameters of porous materials, such as porosity, mean pore size, pore size distribution or strut shape can be controlled during the manufacturing process by adjustment of foaming powders or foaming gas. The microstructure of open-porous foams is complex and irregular, which rules out the possibility to apply analytical approaches for studying such materials. Rapid increase in computational power in recent years, together with the development of more efficient algorithms made modeling of open-porous structure possible.

Various models have been proposed in the literature in order to properly describe the complexity of the structure, representing crucial features of real porous structures. Models representing the structure by ordered set based on regular polyhedrons (usually tetracaidecahedrons) are frequently used in studies on the properties of open porous materials [3]-[5]. It turns out that - despite the random structure - a set of macroscopic properties of porous structures can be modeled with sufficient accuracy with the use of regular geometry. Experimental observations, however, clearly indicate the distribution of pore size [6] and sometimes anisotropy in real materials, which makes such simplified models insufficiently accurate. In order to increase consistency of models with real materials other approaches for simulating properties of porous materials have been developed, namely tessellation methods and methods based on computed tomography. In tessellation methods the volume of representative cell of the material is divided to smaller polyhedral volumes taking into account predefined size and distribution. Different variants of Voronoi tessellations are successfully applied to represent the random nature of foam materials [7], [8], most commonly Laguerre-Voronoi tessellations (LVT) [9]-[11]. This algorithm, applied also by the authors of this study, enables one to develop a model of foam materials with controlled pore size distribution. $2 \mathrm{D} / 3 \mathrm{D}$ reconstruction methods [12]-[14] have also drawn the attention 
of scientist in recent years, where model of geometry is developed on the basis of reconstruction and processing of tomographic image and subsequently used in dedicated software for simulations.

Quantitative relationships between microstructural parameters and porous materials properties is the main goal of most of the studies applying models of porous structures found in literature [15]-[17]. Heat transfer in foam materials is also a subject described in scientific research. A wide literature review in this area has been performed by Zhao [18]. Thermal conductivity of porous materials has been reported to be strongly influenced by porosity. The influence of mean pore size (expressed in pores per inch - ppi) on heat transfer properties of porous materials is a subject undertaken in research performed by Bağc1 and Dukhan [19]. Also the influence of strut shape on thermal properties of porous materials has been studied [20]. Our previous study exhibited the influence of pore size distribution on the permeability of open-porous foams [21].

The aim of this study is to develop numerical model properly representing commercial copper foams. Commercial materials are characterized with the use of micro-computed tomography, serving as reference structures for the development of numerical design procedure. The developed model is based on Laguerre-Voronoi tessellations. The purpose of the model is to enable numerical modeling of heat and mass transfer processes for further studies of microstructure influence on utility parameters of open-porous metallic foams. A set of numerical simulations has been performed employing the finite volume method, in order to verify applicability of the developed model.

\section{MATERIALS AND METHODS}

\subsection{Commercial copper foams tomography}

Commercial copper foams for heat transfer applications were used as reference for the design of virtual models. Foams with pore size of 10 ppi have been studied with use of SkyScan XRadia XCT-400 in order to determine their structural parameters. Porosity, mean pore diameter and mean strut diameter have been determined for validation of the virtual models generated by the design procedure. Three-dimensional image acquisition has been performed under acceleration voltage of $150 \mathrm{kV}$ and current of 50A, which assured a voxel resolution of 41.49 microns. A more detailed description of the applied methodology can be found in Regulski et al. [22].

\subsection{Numerical model of open-porous foams}

Numerical models of complex porous geometries were designed by using of LaguerreVoronoi tessellations algorithm. LVT enables generation open-cell porous structures with predefined porosity, mean pore size and pore size variation. More details about the modeling procedure can be found in Wejrzanowski et al. [11]. Adaptation of the described procedure included mainly the adaptation of cell strut shape. In our previous studies we used cylindrical strut shape, since the model was based on alumina foams applied as filters for molten metals. Strut shape of copper foams studied within the present work clearly indicates struts which are narrow between the triple points and thicker at the connections. Proposed model strut shape is shown in Fig. 1. 


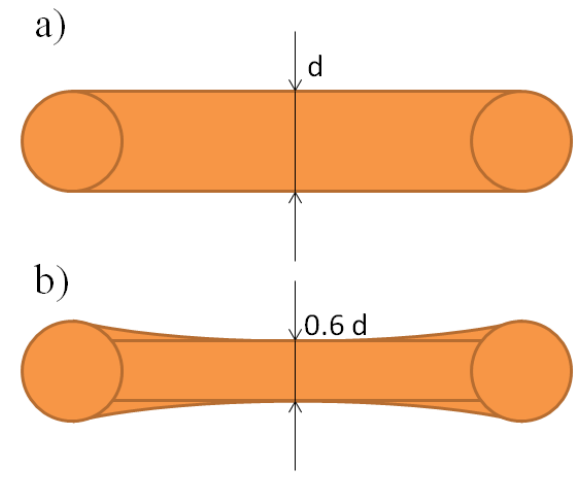

Figure 1: Cross-section of a single strut: (a) Standard; (b) Modified LVT procedure.

\subsection{Temperature transfer efficiency calculations}

Temperature transfer efficiency of the studied materials has been determined with use of finite element method (FEM) implemented in ANSYS Fluent software. Numerical simulations of fluid flowing through the heated copper foam with constant temperature in order to determine temperature transfer efficiency of the material. Studied material was placed in rectangular calculation channel, where fluid flow was applied. Navier-Stokes equations for Newtonian fluid at steady state have been solved with assumption of constant temperature of $352.5 \mathrm{~K}$ on the walls of the foam structure. Temperature value has been chosen based on working temperature of cross-flow heat exchanger with copper foam as a heating material. Temperature transfer coefficient $\mu \mathrm{T}$ was be calculated:

$$
\mu T=\frac{\left(T_{3}-T_{1}\right)}{\left(T_{2}-T_{1}\right)},
$$

where $T_{1}$ is the inlet temperature, $T_{2}$ is the struts temperature and $T_{3}$ is the outlet temperature. Performed mesh convergence study indicated a mesh size of approximately 7 million elements to be optimal for valid representation of the microstructure of the samples. The aim of initial calculations performed within the presented study was to verify the utility of the developed modelling method for further studies of the influence of structural parameters on utility properties of the materials.

\section{RESULTS AND DISCUSSION}

The goal of the performed studies was to characterize open-porous copper foam structures, indicating crucial structural parameters that would serve as guidelines for development of numerical model. The developed model, properly representing complexity of the foam structure, will allow for further studying the influence of chosen structural parameters on utility properties of open-cell metallic foams.

\subsection{Characterization of copper foams}

The images obtained with computer tomography has been analysed with CTAn software in order to determine crucial structural parameters of studied foams. Parameters obtained are listed in Table 1. 
Table 1: Microstructural parameters of 10 ppi commercial copper foams.

\begin{tabular}{|c|c|c|c|c|}
\hline Structure & $\begin{array}{c}10 \mathrm{ppi} \\
\text { No 1 }\end{array}$ & $\begin{array}{c}10 \mathrm{ppi} \\
\text { No 2 }\end{array}$ & $\begin{array}{c}10 \mathrm{ppi} \\
\text { No 3 }\end{array}$ & $\begin{array}{c}\text { Standard } \\
\text { deviation }\end{array}$ \\
\hline Porosity (\%) & 90.98 & 90.37 & 91.19 & $+/-0.82$ \\
\hline Mean pore diameter $(\mathrm{mm})$ & 3.753 & 3.836 & 3.917 & $+/-0.164$ \\
\hline Mean strut diameter $(\mathrm{mm})$ & 1.144 & 1.192 & 1.137 & $+/-0.055$ \\
\hline
\end{tabular}

Avizo software has been employed in order to visualize the studied sample and to perform assessment of the strut shape. An example of reconstructed 3D copper foam structure is shown in Fig. 2.

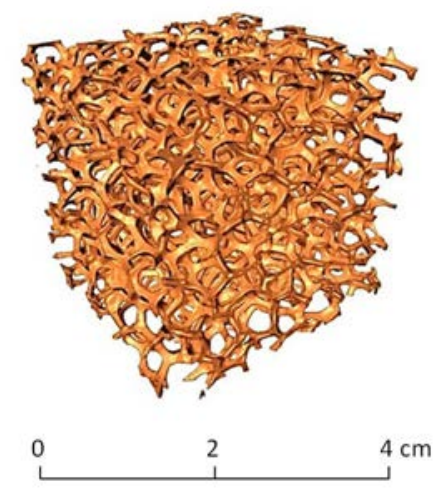

Figure 2: Reconstruction of tomography results of 10 ppi open-porous copper foam.

\subsection{Numerical model of open-porous foams}

A set of 11 structures with coefficient of pore volume variation $\mathrm{CV}(\mathrm{V})$ ranging from 0.45 to 2.0 was developed. Coefficient of pore volume variation was set using a selected range of sphere diameters in the first step of LVT procedure described above. The value of $C V(V)$ for each structure was calculated as CV(V) for LVT cells. Each structure was limited by a bounding box of cubic shape and consisted of 200 pores. According to the literature data [12], [23] this is expected to be sufficiently high number of pores to study their effect on the properties of the structures in question. Mean strut diameter value was $1.0 \mathrm{~mm}$ in accord with data obtained from materials characterisation. This resulted in porosity of $\sim 91 \%$, which is in accord with porosity of commercial materials (Table 2).

An example of the designed structure is shown in Fig. 2.

\subsection{Temperature transfer efficiency calculations}

Temperature transfer efficiency of the designed models has been determined with use of ANSYS Fluent software. The inlet temperature of the fluid was $300 \mathrm{~K}$ (room temperature), the temperature of the struts was chosen in accord with working temperature of commercial materials, $352.5 \mathrm{~K}$, and the inlet velocity was $5 \mathrm{~cm} / \mathrm{s}$. Calculated values have been plotted vs. 
Table 2: Microstructural parameters designed model foams.

\begin{tabular}{|c|c|c|c|}
\hline Structure & Porosity (\%) & $\begin{array}{c}\text { Mean strut } \\
\text { diameter } \\
(\mathrm{mm})\end{array}$ & $\begin{array}{c}\text { Coefficient of pore } \\
\text { size variation } \\
(-)\end{array}$ \\
\hline Model 1 & 91.07 & 1.00 & 0.478 \\
\hline Model 2 & 91.08 & 1.00 & 0.484 \\
\hline Model 3 & 91.07 & 1.00 & 0.459 \\
\hline Model 4 & 91.06 & 1.00 & 0.587 \\
\hline Model 5 & 91.31 & 1.00 & 0.859 \\
\hline Model 6 & 91.41 & 1.00 & 0.640 \\
\hline Model 7 & 91.25 & 1.00 & 1.400 \\
\hline Model 8 & 91.21 & 1.00 & 1.223 \\
\hline Model 9 & 91.32 & 1.00 & 1.391 \\
\hline Model 10 & 91.58 & 1.00 & 1.433 \\
\hline Model 11 & 91.61 & 1.00 & 1.740 \\
\hline
\end{tabular}



Figure 3: Numerical model of open-porous foam obtained with developed LVT design procedure.

coefficient of pore size variation $\mathrm{CV}(\mathrm{V})$ in Fig. 3 in order to determine the influence of pore size distribution (dimensionless coefficient of pore size variation) on temperature transfer efficiency of the materials.

The results clearly indicate the influence of pore size variation on the heat transfer properties of metallic foams. With increasing value of pore size variation coefficient, the temperature transfer efficiency of the material drops. This phenomenon can be explained with higher permeability of the materials with higher inhomogeneity of the pore size. Structures with homogeneous pore size distribution have lower permeability [21], hence they retain flowing fluid easier, facilitating the heat exchange. The effect can also be assigned to constrictivity, a factor determining narrow connections between the neighbouring pores, however this is just an assumption, and separate research needs to be conducted in order to confirm such influence on heat exchange phenomena. 


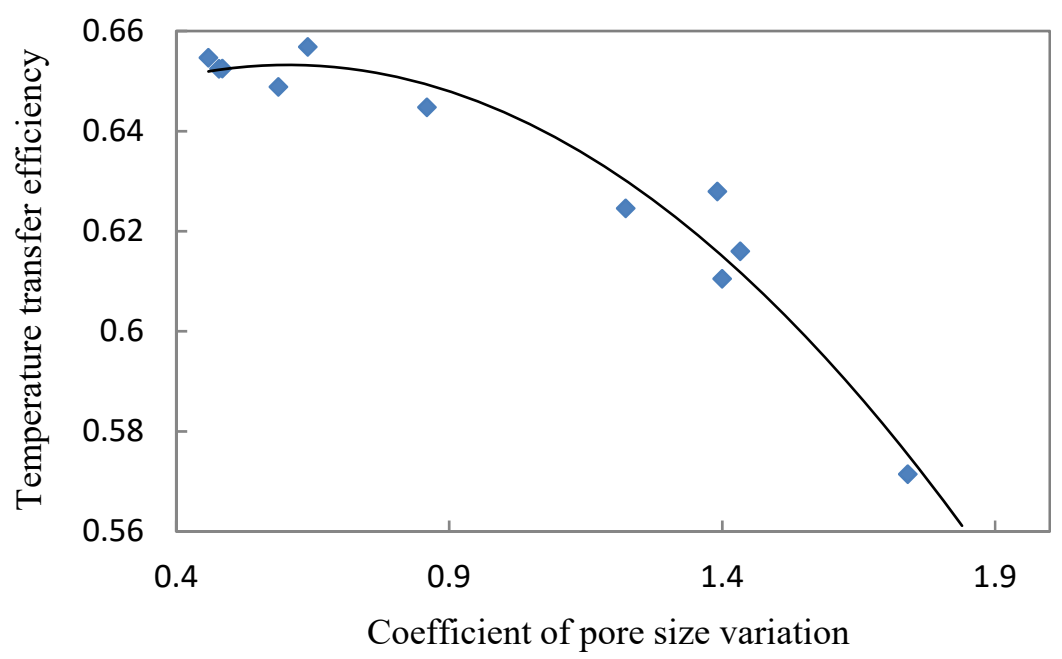

Figure 4: Calculated temperature transfer efficiency of the designed open-cell foams.

\section{CONCLUSIONS}

Commercial open-porous copper foams were characterized with use of computer tomography. Numerical model of open-porous metallic foams, employing LVT tessellations, has been developed based on the structural parameters of characterised materials. The developed model has been applied to develop a representative set of 11 structures with various pore size distribution. Calculations of temperature transfer efficiency has been performed with use of finite volume method in order to assess the ability of the developed materials design method to study the influence of structural parameters on utility properties of open-porous ceramic materials.

The results obtained indicate a strong influence of pore size distribution on heat transfer properties of open-cell copper foams. Lower temperature transfer efficiency values have been obtained for higher values of coefficient of pore size variation. Further research is necessary in order to determine the influence of structural parameters on heat transfer properties of foams. More structures need to be designed and tested including different inlet velocities, range of material porosities. Nevertheless, the results obtained confirmed the utility of the developed design procedure for application in further research of the influence of structural parameters on utility properties of open-porous metallic foams.

\section{ACKNOWLEDGEMENTS}

This work was financially supported by the Polish National Science Centre in the framework of the SONATINA research project (Grant no. 2018/28/C/ST8/00311).

\section{REFERENCES}

[1] Han, X.-H., Wang, Q., Park, Y.-G. T'Joen, C., Sommers, A. \& Jacobi, A., A review of metal foam and metal matrix composites for heat exchangers and heat sinks. Heat Transf. Eng., 33, pp. 991-1009, 2012. DOI: 10.1080/01457632.2012.659613.

[2] Banhart, J., Manufacture, characterisation and application of cellular metals and metal foams. Prog. Mater. Sci., 46, pp. 559-632, 2001. DOI: 10.1016/S00796425(00)00002-5. 
[3] Liu, R. \& Antoniou, A., A relationship between the geometrical structure of a nanoporous metal foam and its modulus. Acta. Mater., 61, pp. 2390-2402, 2013. DOI: 10.1016/j.actamat.2013.01.011.

[4] Pia, G. \& Delogu, F. On the elastic deformation behavior of nanoporous metal foams. Scr. Mater., 69, pp. 781-784, 2013. DOI: 10.1016/j.scriptamat.2013.08.027.

[5] Ko, W.L., Deformations of foamed elastomers. J. Cell. Plast., 1, pp. 45-50, 1965. DOI: $10.1177 / 0021955 X 6500100107$.

[6] Lautensack, C. \& Sych, T., 3D Image analysis of open foams using random tessellations. Image Anal. Stereol., 25 pp. 87-93, 2006. DOI: 10.5566/ias.v25.

[7] Watson, D., Spatial tessellations: concepts and applications of Voronoi diagrams, Comput. Geosci., 19, pp. 1209-1210, 1993. DOI: 10.1016/0098-3004(93)90024-Y.

[8] Ferenc, J.S. \& Néda, Z., On the size distribution of Poisson Voronoi cells. Physica. A., 385, pp. 518-526, 2007. DOI: 10.1016/j.physa.2007.07.063.

[9] Redenbach, C., Microstructure models for cellular materials. Comput. Mater. Sci., 44, pp. 1397-1407, 2009. DOI: 10.1016/j.commatsci.2008.09.018.

[10] Wejrzanowski, T., Haj Ibrahim, S., Skibiński, J., Cwieka, K. \& Kurzydlowski, K.J., Appropriate models for simulating open-porous material. Image. Anal. Stereol., 36, pp. 107-112, 2017.

[11] Wejrzanowski, T., Skibinski, J., Szumbarski, J. \& Kurzydlowski, K.J., Structure of foams modeled by Laguerre-Voronoi tessellations. Comput. Mater. Sci., 67, 2013. DOI: 10.1016/j.commatsci.2012.08.046.

[12] Veyhl, C., Belova, I.V., Murch, G.E. \& Fiedler, T., Finite element analysis of the mechanical properties of cellular aluminium based on micro-computed tomography. Mater. Sci. Eng. A., 528, pp. 4550-4555, 2011. DOI: 10.1016/j.msea.2011.02.031.

[13] Magnico, P., Analysis of permeability and effective viscosity by CFD on isotropic and anisotropic metallic foams. Chem. Eng. Sci., 64, pp. 3564-3575, 2009. DOI: 10.1016/j.ces.2009.04.036.

[14] Westhoff, D., Skibinski, J., Šedivý, O., Wysocki, B., Wejrzanowski, T. \& Schmidt, V., Investigation of the relationship between morphology and permeability for open-cell foams using virtual materials testing. Mater. Des., 147, pp. 1-10, 2018.

[15] Haj Ibrahim, S., Skibiński, J., Oliver, G.J. \& Wejrzanowski, T., Microstructure effect on the permeability of the tape-cast open-porous materials. Mater. Des., 167, 2019.

[16] Bhattacharya, A., Calmidi, V.V. \& Mahajan, R.L., Thermophysical properties of high porosity metal foams. Int. J. Heat Mass Transf., 45, pp. 1017-1031, 2002. DOI: 10.1016/S0017-9310(01)00220-4.

[17] Wejrzanowski, T. et al., Multi-modal porous microstructure for high temperature fuel cell application. J. Power Sources, 373, pp. 85-94, 2018.

[18] Zhao, C.Y., Review on thermal transport in high porosity cellular metal foams with open cells. Int. J. Heat Mass Transf., 55, pp. 3618-3632, 2012. DOI: 10.1016/j.ijheatmasstransfer.2012.03.017.

[19] Bağc1, Ö. \& Dukhan, N., Experimental hydrodynamics of high-porosity metal foam: Effect of pore density. Int. J. Heat Mass Transf., 103, pp. 879-885, 2016. DOI: 10.1016/j.ijheatmasstransfer.2016.07.097.

[20] Ambrosio, G., Bianco, N., Chiu, W.K.S., Iasiello, M., Naso, V. \& Oliviero, M., The effect of open-cell metal foams strut shape on convection heat transfer and pressure drop. Appl. Therm. Eng., 103, pp. 333-343, 2016.

DOI: $10.1016 /$ j.applthermaleng.2016.04.085. 
[21] Skibinski, J., Cwieka, K., Kowalkowski, T., Wysocki, B., Wejrzanowski, T. \& Kurzydlowski, K.J., The influence of pore size variation on the pressure drop in opencell foams. Mater. Des., 87, pp. 650-655, 2015. DOI: 10.1016/j.matdes.2015.08.079.

[22] Regulski, W. et al., Pressure drop in flow across ceramic foams-A numerical and experimental study. Chem. Eng. Sci., 137, 2015.

[23] Roberts, P. \& Garboczi, E.J., Elastic properties of model porous ceramics. J. Am. Ceram. Soc., 83 pp. 3041-3048, 2000. DOI: 10.1111/j.1151-2916.2000.tb01680.x, 10.1016/j.ces.2015.06.043. 